\title{
Systematic Review and Meta-Analysis of the Palatal Surgeries in the Treatment of Obstructive Sleep Apnea
}

\author{
Amr Nabil Rabie', Ossama Mady¹, Ahmed Negm El-Shazly², Alaa Abouzeid ${ }^{2}$ \\ ${ }^{1}$ Department of Otolaryngology/Head and Neck Surgery, Faculty of Medicine, Ain Shams University, Cairo, Egypt \\ ${ }^{2}$ Department of Otolaryngology/Head and Neck Surgery, Misr University for Science and Technology, Cairo, Egypt \\ Email: arabie@live.com,Omady84@gmail.com,negm_oto@yahoo.com, alaaaabozeid96@gmail.com
}

How to cite this paper: Rabie, A.N., Mady, O., El-Shazly, A.N. and Abouzeid, A. (2021) Systematic Review and Meta-Analysis of the Palatal Surgeries in the Treatment of Obstructive Sleep Apnea. International Journal of Otolaryngology and Head \& Neck Surgery, 10, 61-74. https://doi.org/10.4236/ijohns.2021.102007

Received: October 19, 2020

Accepted: March 1, 2021

Published: March 4, 2021

Copyright $\odot 2021$ by author(s) and Scientific Research Publishing Inc. This work is licensed under the Creative Commons Attribution International License (CC BY 4.0).

http://creativecommons.org/licenses/by/4.0/ (c) (i) Open Access

\begin{abstract}
Background: This paper aims to examine published articles between January 2008 and January 2019 on the different palatal surgeries performed on OSA patients and the treatment outcomes, which in turn will be used to determine the effectiveness of various palatal surgical techniques in treating OSAS and the most effective of the palatal surgical techniques in treating OSAS. Patients and Methods: The current review followed the guidelines of preferred reporting items for systematic reviews and meta-analysis statement 2009 (PRISMA). The quality of relevant studies was assessed using NIH quality assessment tool for observational cohort and cross-sectional studies as well as $\mathrm{NIH}$ tool for quality assessment for case series studies. Results: Meta-analyses of relevant studies showed that the surgical technique that achieved the best reduction on AHI (Apnea/Hypopnea Index) was the lateral pharyngoplasty followed by the Anterior Palatoplasty, with a significant mean reduction of $[(\mathrm{SMD}=-0.848,95 \% \mathrm{CI}(-1.209-0.487), \mathrm{p}$-value $<0.001)$ and $(\mathrm{SMD}=$ $-0.864,95 \%$ CI $(-1.234--0.494)$, p-value $<0.001)$, respectively]. The technique responsible for the best improvement in Epworth Sleepiness Score (ESS) was the Relocation Pharyngoplasty, with a significant mean reduction of [SMD $=-0.998,95 \%$ CI $(-1.253--0.743)$, p-value $<0.001]$. Minimal $\mathrm{O}_{2}$ saturation level improved most with the Expansion Sphincter Pharyngoplasty, with a significant mean reduction of $[\mathrm{SMD}=1.011,95 \%$ CI $(0.581$ $1.440)$, p-value $<0.001]$. The surgical procedure that results in the best post-operative Visual Analogue Scale (VAS) was Z-Palatoplasty, with a significant mean reduction of [SMD $=-1.551,95 \%$ CI $(-2.049--1.052)$, p-value $<0.001]$. Soft palate length changes with a significant mean reduction of [SMD $=-2.219,95 \%$ CI $(-2.730--1.708)$, p-value $<0.001]$. Finally, meta-analyses of relevant studies showed that expansion sphincter pharyngoplasty achieved the overall highest success rate [event rate $=77 \%, 95 \% \mathrm{CI}$
\end{abstract}


$(65.4 \%-85.5 \%)$, p-value $<0.001]$. Conclusion: The best procedure for treating OSA varies from patient to patient and there is no universal cure-all. Careful patient selection and pre-operative evaluation are mandatory.

\section{Keywords}

Obstructive Sleep Apnea, Palatal Surgery, ESS, AHI, VAS, Oxygen Saturation, Meta-Analysis, Systematic Review

\section{Introduction}

Charles Dickens in “The Posthumous Papers of the Pickwick Club” published the first description of a patient with obstructive sleep apnea in 1836 [1]. Subsequently, Guilleminault coined the term "upper airway resistance syndrome" in 1993 [2]. There are three types of sleep apneas: Central, Obstructive and Mixed. Central sleep apnea occurs when the brain does not send the signal to the muscles to take a breath. Obstructive sleep apnea happens when the brain sends the instruction to the muscles and the muscles make an effort to take a breath, but they are struggling because the airway becomes obstructed and prevents an adequate flow of air. Mixed sleep apnea is defined when there is both central sleep apnea and obstructive sleep apnea. Obstructive Sleep Apnea is a common condition affecting $4 \%$ of men and $2 \%$ of women [3]. Presenting symptoms are variable including restless sleep, snoring, excessive daytime somnolence, fatigue, memory loss, decreased cognitive function, mood changes, nocturnal enuresis, nocturnal sweating and observed choking or gasping at night. People with Obstructive Sleep Apnea (OSA) seek help for different reasons. At one end of the spectrum are patients presented with morbid obesity, carbon dioxide retention, hypertension, and right-sided heart failure with an Apnea Index of more than 100. At the other end of the spectrum are those individuals with minimal sleep-disordered breathing whose chief complaint is snoring [4].

We are presenting a systematic review for published articles between January 2008 and January 2019 on the different palatal surgeries performed on OSA patients and the treatment outcomes that could determine the effectiveness of various palatal surgical techniques in treating OSA including those being the most effective in treating OSA.

\section{Patients and Methods}

The current review followed the guidelines of preferred reporting items for systematic reviews and meta-analysis statement 2009 (PRISMA) [5]. The detailed steps of methods were described elsewhere as well as PRISMA checklist [6].

The quality of relevant studies was assessed using NIH quality assessment tool for.

Observational cohort and cross-sectional studies as well as NIH tool for quality assessment for case series studies. (Study Quality Assessment Tools) "Na- 
tional Heart, Lung, and Blood Institute (NHLBI)" 2019. Regarding cross section and cohort studies, each study was given a score out of 14 based on answering each question ( $\mathrm{Yes}=1, \mathrm{No}=0, \mathrm{NA}=0$ ). A score of $10-14$ indicated a good quality article, 5 - 9 for fair, and 1 - 4 for poor quality article. Regarding case series studies, total evaluation score was 9 , a score from 7 - 9 indicated good quality article, whereas score from $4-6$ for fair, and $1-3$ for poor quality article.

Statistical analysis was performed as the following: prior to analysis phase, if the published study only reported the mean, the estimated standard deviation (SD) was derived from linear regression of log (published SDs) against log (published means) according to Van Rijkom, H. M., Truin, G. J., \& Van't Hof, M. A. (1998) [7]. The published SDs and means were collected from other includes studies. If there was one study with more than one publication reports, they were compared and the publications with complete data set were used. We made pairwise meta-analyses of our outcomes using Comprehensive Meta-Analysis software (CMA version 3) [8]. Standardized mean difference (SMD) with the corresponding $95 \%$ confidence intervals (95\% CI) was also calculated. Pooled event rate with the corresponding $95 \%$ confidence intervals $(95 \% \mathrm{CI}$ ) was also calculated. A fixed-effects model was used when there was no heterogeneity. Heterogeneity was assessed with Q statistics and $\mathrm{I}^{2}$-test considering it significant with $\mathrm{I}^{2}$ value $>50 \%$ or $\mathrm{p}$-value $<0.10$. Publication bias was assessed with the Egger's regression test [9] and represented graphically by Begg's funnel plot when there were ten or more studies. Egger's regression test $\mathrm{p}$-value $<0.05$ was considered significant. Whenever publication bias was found, the trim and fill method of Duvall and Tweedie was applied adding studies that appeared to be missing to enhance the symmetry [10].

\section{Results}

\subsection{Literature and Study Characteristics}

As depicted in Figure 1, electronic search yielded 1036 articles from two databases. After 121 duplicates were removed, 863 articles were screened in title/abstract screening, while 377 articles were screened in full text screening for inclusion. Finally, 52 articles were included in the qualitative and quantitative meta-analysis synthesis. The manual search resulted in no additional studies. Detailed characteristics of the included studies are shown in Table 1. The surgical steps of the main palatal techniques encountered during out systematic review are outlined in Table 2.

\subsection{Risk of Bias Assessment}

With regard to quality assessment, 44 of 52 studies evaluated showed good quality, whereas the other eight studies showed fair quality (Table 1).

\subsection{Outcomes}

\section{1) AHI (Apnea/Hypopnea Index)}


Table 1. Characteristics of the studies included in the meta-analysis.

\begin{tabular}{|c|c|c|c|c|c|c|}
\hline Reference ID & $\begin{array}{l}\text { Sample } \\
\text { size }\end{array}$ & $\begin{array}{l}\text { Type of } \\
\text { Study }\end{array}$ & $\begin{array}{l}\text { Technique } \\
\text { used }\end{array}$ & Type of surgery & $\begin{array}{c}\text { Follow up } \\
\text { period (Months) }\end{array}$ & $\begin{array}{c}\mathrm{QA} \\
\text { assessment }\end{array}$ \\
\hline Amali/2017/Iran & 20 & Prospective & UPPP & Classic Palatoplasty & 6 & Good \\
\hline Amali/2017/Iran & 20 & Prospective & MRTA & Classic Palatoplasty & 6 & Good \\
\hline Adzreil/2016/Malaysia & 31 & Prospective & $\mathrm{AP}+\mathrm{TBD}$ & Anterior Palatoplasty & 12 & Good \\
\hline Atan/2017/Turkey & 14 & Prospective & $\mathrm{AP}+\mathrm{MESP}$ & Antero-lateral Palatoplasty & 6 & Good \\
\hline Binar/2016/Turkey & 23 & Prospective & ESP & Lateral Palatoplasty & 3 & Good \\
\hline Browaldh/2013/Sweden & 32 & Prospective & UPPP & Classic Palatoplasty & 6 & Good \\
\hline Cammaroto/2017/Italy & 10 & Retrospective & UPPP & Classic Palatoplasty & 6 & Good \\
\hline Cammaroto/2017/Italy & 10 & Retrospective & ESP & Lateral Palatoplasty & 6 & Good \\
\hline Cammaroto/2017/Italy & 10 & Retrospective & $\mathrm{BRP}$ & Lateral Palatoplasty & 6 & Good \\
\hline Carrasco-Llatas/2015/Spain & 10 & Retrospective & LP & Lateral Palatoplasty & 7 & Good \\
\hline Carrasco-Llatas/2015/Spain & 7 & Retrospective & UPPP & Classic Palatoplasty & 7 & Good \\
\hline Carrasco-Llatas/2015/Spain & 10 & Retrospective & EP & Lateral Palatoplasty & 7 & Good \\
\hline Carrasco-Llatas/2015/Spain & 4 & Retrospective & $\mathrm{ZP}$ & Lateral Palatoplasty & 7 & Good \\
\hline Carrasco-Llatas/2015/Spain & 22 & Retrospective & PPR & Classic Palatoplasty & 7 & Good \\
\hline Chen/2015/Taiwan & 32 & Retrospective & $\mathrm{RP}$ & Antero-lateral Palatoplasty & 6 & Good \\
\hline Cheng/2008/Taiwan & 50 & Prospective & MEUP & Anterior Palatoplasty & 6 & Fair \\
\hline Chi/2014/Taiwan & 25 & Prospective & LP & Lateral Palatoplasty & 6 & Good \\
\hline Cho K-S/2013/South Korea & 23 & Prospective & LPMR & Anterior Palatoplasty & 6 & Good \\
\hline Choi/2013/Korea & 20 & Prospective & UPPP & Classic Palatoplasty & 6 & Good \\
\hline Despeghel/2016/Belgium & 19 & Prospective & ESP & Lateral Palatoplasty & 6 & Good \\
\hline DizdaR/2015/Turkey & 9 & Prospective Cohort & UPPP & Classic Palatoplasty & 20 & Good \\
\hline Dizdar/2015/Turkey & 14 & Prospective & LP & Lateral Palatoplasty & 20 & Good \\
\hline El-Anwar/2016/Egypt & 24 & Prospective & $\mathrm{EP} \mathrm{w} / \mathrm{SS}$ & Lateral Palatoplasty & 6 & Good \\
\hline El-Anwar/2017/Egypt & 22 & Prospective & DSS-ESP & Antero-lateral Palatoplasty & 6 & Good \\
\hline Elbassiouny/2014/Egypt & 28 & Prospective & SPFP & Lateral Palatoplasty & 6 & Good \\
\hline Elbassiouny/2016/Egypt & 21 & Prospective & SPWF & Antero-lateral Palatoplasty & 6 & Good \\
\hline Emara/2016/Egypt & 38 & Prospective & AAP & Anterior Palatoplasty & 6 & Good \\
\hline Guler/2018/Turkey & 81 & Retrospective & ESP & Lateral Palatoplasty & 3 & Good \\
\hline Karakoc/2018/Turkey & 28 & Prospective & LP & Lateral Palatoplasty & 6 & Good \\
\hline Karakoc/2018/Turkey & 31 & Prospective & ESP & Lateral Palatoplasty & 6 & Good \\
\hline Karakoc/2018/Turkey & 20 & Prospective & $\mathrm{AP}$ & Anterior Palatoplasty & 6 & Good \\
\hline Kim/2013/South Korea & 92 & Prospective & $\mathrm{UPF}+\mathrm{LP}$ & Lateral Palatoplasty & 6 & Good \\
\hline Lee/2010/Italy & 30 & Prospective & $\mathrm{RP}$ & Antero-lateral Palatoplasty & 6 & Fair \\
\hline
\end{tabular}




\begin{tabular}{|c|c|c|c|c|c|c|}
\hline Li/2009/Taiwan & 10 & Prospective & $\mathrm{RP}$ & Antero-lateral Palatoplasty & 6 & Fair \\
\hline Li/2013/Taiwan & 47 & Prospective & $\mathrm{RP}$ & Antero-lateral Palatoplasty & 6 & Good \\
\hline Li/2015/Taiwan & 32 & Prospective & $\mathrm{RP}$ & Antero-lateral Palatoplasty & 6 & Good \\
\hline Li/2016/Taiwan & 60 & Retrospective & $\mathrm{RP}$ & Antero-lateral Palatoplasty & 6 & Good \\
\hline Li/2018/Taiwan & 25 & Retrospective & SP & Lateral Palatoplasty & 6 & Good \\
\hline Liu/2013/China & 51 & Retrospective & H-UPPP/ Z-PPP & Classic Palatoplasty & 9 & Good \\
\hline Lunkvist/2008/Sweden & 120 & Prospective & UPPP & Classic Palatoplasty & 12 & Fair \\
\hline Mantovani/2012/Italy & 4 & Prospective & VUPL & Lateral Palatoplasty & 6 & Fair \\
\hline Mantovani/2015/Italy & 32 & Prospective & $\mathrm{BRB}$ & Lateral Palatoplasty & 12 & Good \\
\hline Mantovani/2017/Italy & 19 & Prospective & Alianza & Lateral Palatoplasty & 6 & Good \\
\hline Marzetti/2013/Italy & 15 & Prospective & $\mathrm{AP}$ & Anterior Palatoplasty & 2 & Good \\
\hline Marzetti/2013/Italy & 19 & Prospective & UPF & Anterior Palatoplasty & 2 & Good \\
\hline Montevecchi/2017/Italy & 111 & Prospective & BRP & Lateral Palatoplasty & 6 & Good \\
\hline Neruntarat/2011/Thailand & 83 & Prospective & UPF & Anterior Palatoplasty & 55 & Fair \\
\hline Pang/2009/Multi-center & 77 & Prospective & $\mathrm{AP}$ & Anterior Palatoplasty & 33 & Fair \\
\hline Pang/2016/Multi-center & 73 & Prospective & $\mathrm{AP}+\mathrm{ESP}$ & Antero-lateral Palatoplasty & 6 & Good \\
\hline Pianta/2017/Italy & 17 & Retrospective & BESP & Lateral Palatoplasty & 6 & Good \\
\hline Piccin/2013/Italy & 85 & Prospective & FEP & Lateral Palatoplasty & 6 & Good \\
\hline Plaza/2019/Multi-center & 75 & Prospective & ESP & Lateral Palatoplasty & 12 & Good \\
\hline Rashwan/2017/Italy & 25 & Prospective & UPPP & Classic Palatoplasty & 6 & Good \\
\hline Rashwan/2017/Italy & 25 & Prospective & ESP & Lateral Palatoplasty & 6 & Good \\
\hline Rashwan/2017/Italy & 25 & Prospective & $\mathrm{BRP}$ & Lateral Palatoplasty & 6 & Good \\
\hline Salamanca/2014/Italy & 24 & Prospective & BAP & Lateral Palatoplasty & 6 & Good \\
\hline Soares/2013/ Brazil & 18 & Prospective & LP & Lateral Palatoplasty & 6 & Good \\
\hline Sommer/2016/Germany & 23 & Prospective & UPPP & Classic Palatoplasty & 3 & Good \\
\hline Suslu/2017/Turkey & 28 & Retrospective & ESP & Lateral Palatoplasty & 6 & Good \\
\hline Ugur/2013/Turkey & 42 & Prospective & AP & Anterior Palatoplasty & 24 & Good \\
\hline Vicini/2015/Italy & 10 & Prospective & BRP & Lateral Palatoplasty & 6 & Good \\
\hline Wu/2016/China & 24 & Prospective & UPPP & Classic Palatoplasty & 6 & Good \\
\hline Yi/2009/China & 34 & Prospective & ZPPP & Classic Palatoplasty & 6 & Fair \\
\hline Yousuf/2013/India & 22 & Prospective Cohort & UPPP & Classic Palatoplasty & 6 & Good \\
\hline
\end{tabular}

UPF: Uvulopalatal Flap; LP: Lateral Pharyngoplasty; RP: Relocation Pharyngoplasty; MEUP: Microdebrider Assisted Extended Uvulopalatoplasty; ESP: Expansion Sphincter Pharyngoplasty; UPPP: Uvulopalatopharyngoplasty; LPMR: Limited Palatal Muscle Resection; SPFP: Soft Palatal Webbing Flap Pharyngoplasty; EP + SS: Expansion Pharyngoplasty with Suspension Sutures; PPR: Partial Palatal Resection; ZP: Z-Palatoplasty; MESP: Modified Expansion Sphincter Pharyngoplasty; DSS + ESP: Double Suspension Sutures + Expansion Sphincter Pharyngoplasty; MRTA: Modified Radiofrequency Tissue Ablation; FEP: Functional Expansion Pharyngoplasty; H-UPPP: Han's Uvulopalatopharyngoplasty; Alianza Technique: BAP + BRB; SPW: Soft Palatal Webbing Flap; SP: Suspension Palatoplasty; BRP: Barbed Reposition Pharyngoplasty; BESP: Barbed Expansion Pharyngoplasty; BAP: Barbed Anterior Palatoplasty; BRB: Barbed Roman Blinds. 
Table 2. Surgical steps of the major palatal surgical techniques.

\begin{tabular}{|c|c|c|c|c|c|c|}
\hline UPPP & UPF & LP & AP & ESP & $\mathrm{RP}$ & Roman Blinds \\
\hline $\begin{array}{l}\text { Bilateral } \\
\text { tonsillectomy } \\
\text { with trimming } \\
\text { and resection } \\
\text { of excess } \\
\text { pharyngeal } \\
\text { mucosa. Arch } \\
\text { shaped incisions } \\
\text { are then made on } \\
\text { either side of the } \\
\text { uvula followed by } \\
\text { blunt dissection } \\
\text { to remove the fat } \\
\text { from the spatium } \\
\text { veli palate. The } \\
\text { free palatal } \\
\text { mucosa is then } \\
\text { sutured together } \\
\text { and the anterior } \\
\text { and posterior } \\
\text { pillars are } \\
\text { sutured together }\end{array}$ & $\begin{array}{l}\text { The Uvula is } \\
\text { reflected } \\
\text { upwards on the } \\
\text { palate and an } \\
\text { outline is } \\
\text { marked. A } \\
\text { diamond } \\
\text { shaped } \\
\text { segment of } \\
\text { mucosa and } \\
\text { submucosa } \\
\text { starting from } \\
\text { the outline } \\
\text { downwards is } \\
\text { removed in } \\
\text { addition to the } \\
\text { anterior aspect } \\
\text { of the uvular } \\
\text { mucosa. The } \\
\text { uvular tip is } \\
\text { shortened. } \\
\text { Finally, the } \\
\text { uvula is then } \\
\text { reflected onto } \\
\text { the soft palate } \\
\text { and sutured } \\
\text { into place }\end{array}$ & $\begin{array}{l}\text { The technique entails } \\
\text { performing a } \\
\text { tonsillectomy. If the } \\
\text { patient had previously } \\
\text { undergone a } \\
\text { tonsillectomy, then a } \\
\text { vertical myotomy is } \\
\text { done in the tonsillar } \\
\text { bed in order to access } \\
\text { the Superior } \\
\text { Pharyngeal } \\
\text { Constrictor (SPC) } \\
\text { muscle. The SPC Is } \\
\text { then vertically } \\
\text { sectioned resulting in } \\
\text { two flaps, the lateral } \\
\text { of which is sutured to } \\
\text { the anterior pillar on } \\
\text { the same side. A half } \\
\text { thickness incision is } \\
\text { made in the oral } \\
\text { aspect of the soft } \\
\text { palate extending } \\
\text { supero-laterally from } \\
\text { the base of the uvula } \\
\text { to the lateral soft } \\
\text { palate margin. The } \\
\text { Palatopharyngeus } \\
\text { muscle is sectioned } \\
\text { transversely. Z plasty } \\
\text { is used to suture the } \\
\text { upper } \\
\text { palatopharyngeal } \\
\text { muscle flap with the opposite side. } \\
\text { palatine flap created } \\
\text { previously. The lower } \\
\text { palatopharyngeal } \\
\text { muscle flap is then } \\
\text { sutured to the } \\
\text { anterior pillar on the } \\
\text { same side. The same } \\
\text { the repeated on }\end{array}$ & $\begin{array}{l}\text { A rectangular strip } \\
\text { of mucosa midway } \\
\text { between the hard } \\
\text { palate and the uvula is } \\
\text { removed down to the } \\
\text { muscle layer without } \\
\text { removing any of the } \\
\text { muscles. The skin } \\
\text { edges are then } \\
\text { approximated thus } \\
\text { bringing the soft } \\
\text { palate } \\
\text { antero-superiorly. } \\
\text { Partial uvulectomy } \\
\text { may be done if needed }\end{array}$ & $\begin{array}{l}\text { Tonsillectomy } \\
\text { followed by } \\
\text { identification and } \\
\text { horizontal transection } \\
\text { of the } \\
\text { Palatopharyngeus } \\
\text { muscle near its } \\
\text { inferior end. A } \\
\text { superolateral incision } \\
\text { is made extending } \\
\text { from the base of the } \\
\text { uvula to the soft } \\
\text { palate margin, in } \\
\text { order to uncover the } \\
\text { arching palatoglossal } \\
\text { fibers of the soft } \\
\text { palate. A suture is } \\
\text { taken through the } \\
\text { bulk of the } \\
\text { Palatopharyngeus } \\
\text { muscle and attached } \\
\text { to the arching } \\
\text { palatoglossal fibers. } \\
\text { The anterior and } \\
\text { posterior pillars are } \\
\text { then sutured together. } \\
\text { The same steps are } \\
\text { repeated on the } \\
\text { opposite side. Partial } \\
\text { Uvulectomy for } \\
\text { patients with enlarged } \\
\text { uvula. }\end{array}$ & $\begin{array}{l}\text { Tonsillectomy is the } \\
\text { first step followed by } \\
\text { bilateral incisions } \\
\text { extending from the } \\
\text { base of the uvula } \\
\text { supero-laterally to a } \\
\text { point (near the } \\
\text { pterygoid hamulus) } \\
\text { and then from there } \\
\text { downwards to } \\
\text { connect to the base } \\
\text { of the anterior pillar. } \\
\text { The mucosa, } \\
\text { submucosa and } \\
\text { adipose tissue in the } \\
\text { superolateral corner } \\
\text { of the palate } \\
\text { bounded by the } \\
\text { incisions made } \\
\text { previously is } \\
\text { dissected. } \\
\text { The } \\
\text { Palatopharyngeus } \\
\text { (PPM) muscle near } \\
\text { the uvula is rotated } \\
\text { supero-laterally to } \\
\text { be sutured to the } \\
\text { area previously } \\
\text { dissected. The } \\
\text { medial aspect of the } \\
\text { sutured to the } \\
\text { remaining PGM } \\
\text { Constrictor muscle } \\
\text { (SPC) is sutured to } \\
\text { the ipsilateral } \\
\text { the ipsilateral } \\
\text { tonsillar fossa. The } \\
\text { remaining PPM is }\end{array}$ & $\begin{array}{l}\text { Three stab incisions } \\
\text { are made in the } \\
\text { palate. Two at } \\
\text { thpterygoid hamulae } \\
\text { and one just before } \\
\text { the posterior nasal } \\
\text { spine. Using a 2-0 } \\
\text { non-resorbable } \\
\text { polyester thread } \\
\text { mounted on a } \\
\text { cutting needle, the } \\
\text { periosteum and } \\
\text { fibromuscular layer } \\
\text { of the posterior nasal } \\
\text { spine is entered } \\
\text { sideways. The thread } \\
\text { is then guided } \\
\text { downwards to the } \\
\text { free edge of the soft } \\
\text { palate using multiple } \\
\text { in and out sutures, } \\
\text { each through the } \\
\text { same hole. The } \\
\text { needle emerges on } \\
\text { one side of the } \\
\text { uvular base and then } \\
\text { passed sideways } \\
\text { through the uvular } \\
\text { base to emerge on } \\
\text { the contralateral } \\
\text { side. The thread is } \\
\text { then passed upwards } \\
\text { towards the } \\
\text { posterior nasal spine } \\
\text { in the same manner } \\
\text { as before. At the } \\
\text { posterior nasal spine, } \\
\text { the thread is tightly } \\
\text { knotted and buried } \\
\text { in the stab incision } \\
\text { which is } \\
\text { subsequently close } \\
\text { using resorbable } \\
\text { thread. The same } \\
\text { steps are repeated } \\
\text { hamulae }\end{array}$ \\
\hline
\end{tabular}




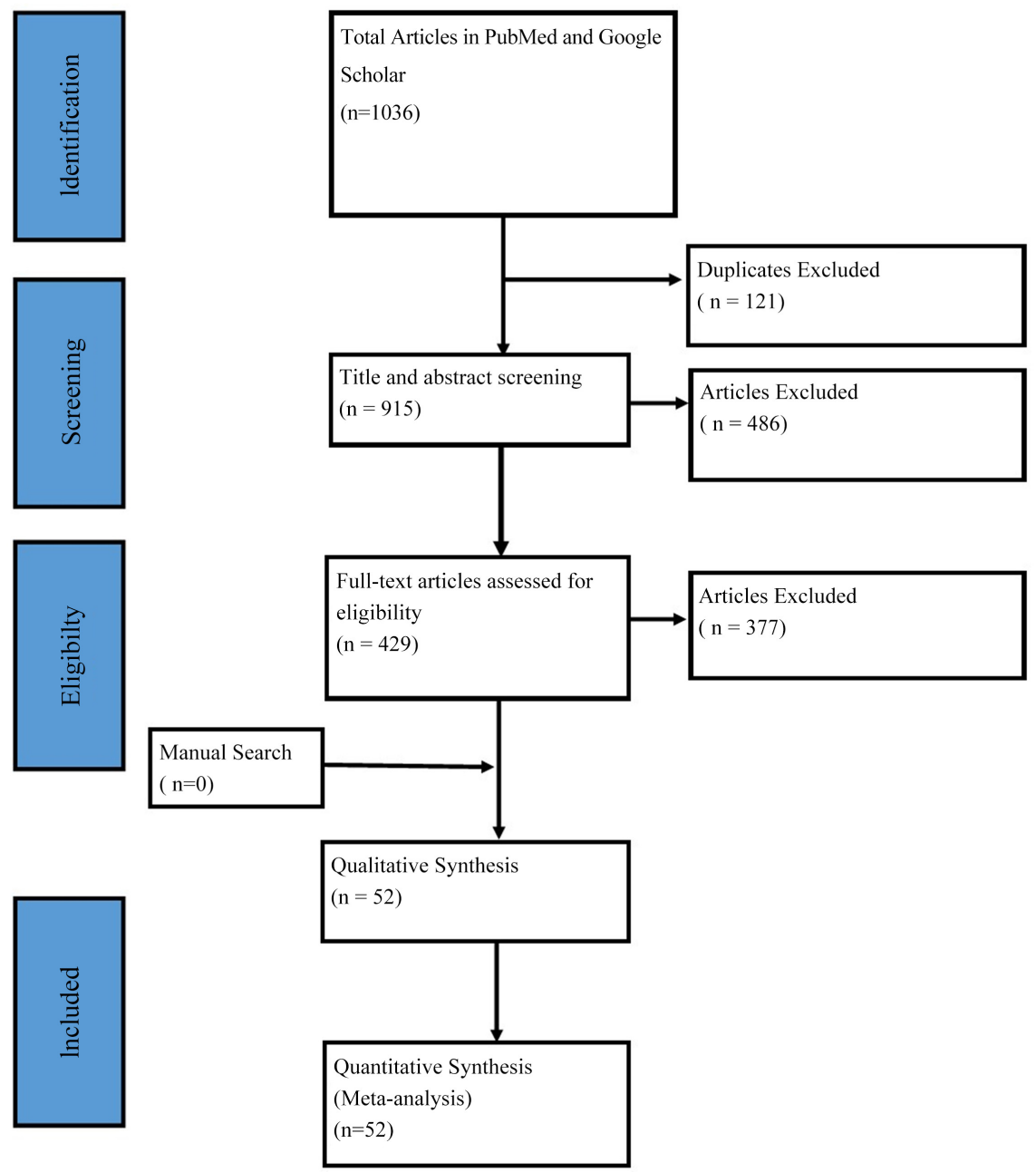

Figure 1. PRISMA flow diagram of the search and review process.

Meta-analyses of relevant studies showed that the surgical technique that achieved the best reduction on AHI was the lateral pharyngoplasty followed by the anterior palatoplasty, with a significant mean reduction of [ $(\mathrm{SMD}=-0.848$, $95 \%$ CI $(-1.209--0.487)$, p-value $<0.001)$ and $(\mathrm{SMD}=-0.864,95 \% \mathrm{CI}(-1.234$ - -0.494 ), p-value $<0.001$ ), respectively] (Figure 2). On the other hand, the surgical technique that achieved the least reduction on AHI was barbed roman blinds, with a significant mean reduction of [SMD $=-4.956,95 \%$ CI $(-6.218-$ -3.693), p-value $<0.001$ ] (Figure 2). The mean reduction of AHI for the classical Uvulopalatopharyngoplasty (UPPP) was [SMD $-1.466,95 \%$ CI $(-1.880$ -1.052), p-value $<0.001$ ] (Figure 2). Random model was used, as heterogeneity was significant with $\mathrm{I}^{2}=87.814$, and $\mathrm{p}$-value $<0.001$.

\section{2) ESS (Epworth Sleepiness Scale)}

Meta-analyses of relevant studies showed that the surgical technique that achieved the best reduction on ESS was the relocation pharyngoplasty, with a significant mean reduction of [SMD $=-0.998,95 \% \mathrm{CI}(-1.253-0.743)$, p-value $<0.001$ ] (Figure 3). On the other hand, the surgical technique that achieved the 
worst reduction on ESS was barbed roman blinds, with a significant mean reduction of [SMD $=-2.448,95 \%$ CI $(-3.149--1.827)$, p-value $<0.001]$ (Figure 3 ). The mean reduction of AHI for the classical UPPP was [SMD -1.388, 95\% CI $(-1.855--0.922)$, p-value $<0.001$ ] (Figure 3). Random model was used, as heterogeneity was significant with $\mathrm{I}^{2}=87.814$, and $\mathrm{p}$-value $<0.001$.

3) Minimal Oxygen Saturation Percentage

\section{Meta-analysis for changes in AHI regards different surgical techniques}

\begin{tabular}{|c|c|c|c|c|c|}
\hline Group by & Statis & istics for & each st & udy & \\
\hline Subgroup within study & $\begin{array}{c}\text { Std diff } \\
\text { in means }\end{array}$ & $\begin{array}{l}\text { Lower } \\
\text { limit }\end{array}$ & $\begin{array}{c}\text { Upper } \\
\text { limit }\end{array}$ & p-Value & Total \\
\hline Anterior Palatoplasty & -0.864 & -1.234 & -0.494 & 0.000 & 185 \\
\hline Barbed Reposition Pharyngoplasty & -1.191 & -1.397 & -0.986 & 0.000 & 156 \\
\hline Barbed Roman Blinds & -4.956 & -6.218 & -3.693 & 0.000 & 32 \\
\hline Expansion Sphincter Pharyngoplasty & -1.890 & -2.413 & -1.368 & 0.000 & 428 \\
\hline Lateral Pharyngoplasty & -0.848 & -1.209 & -0.487 & 0.000 & 95 \\
\hline Miscellaneous & -2.133 & -2.679 & -1.587 & 0.000 & 447 \\
\hline Relocation Pharyngoplasty & -1.429 & -1.701 & -1.157 & 0.000 & 211 \\
\hline Uvulopalatal Flap & -2.099 & -3.759 & -0.439 & 0.013 & 102 \\
\hline Uvulopalatopharyngoplasty & -1.466 & -1.880 & -1.052 & 0.000 & 363 \\
\hline Z-Palatoplasty & -1.157 & -1.568 & -0.746 & 0.000 & 38 \\
\hline Overall & -1.302 & -1.420 & -1.184 & 0.000 & 2057 \\
\hline
\end{tabular}

Random effect model, Heterogeneity: |^2=87.814, P-value<0.001

Figure 2. Meta-analysis for the changes in AHI regarding the different surgical techniques.

Meta-analysis for changes in ESS regards different surgical techniques

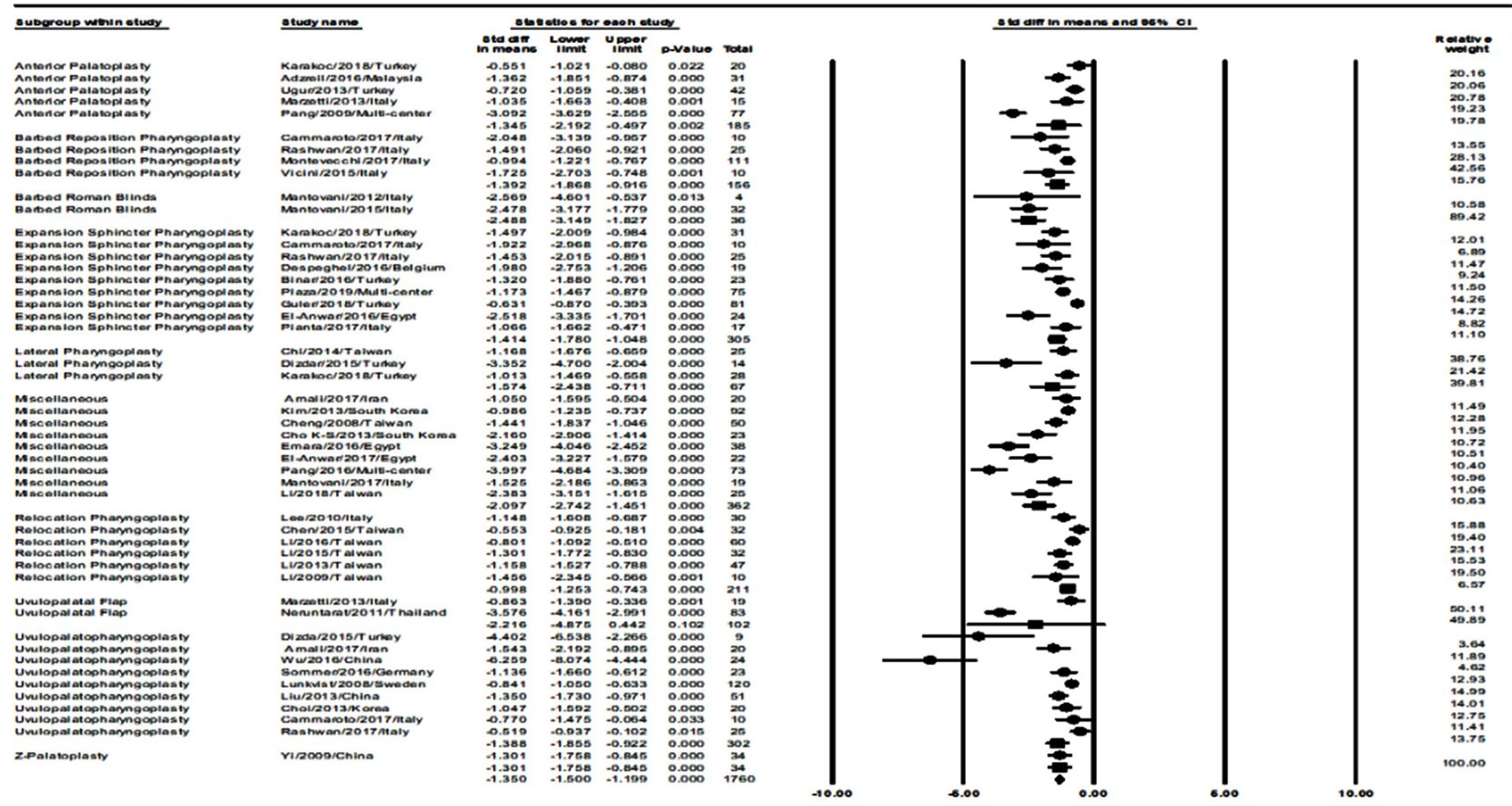

Figure 3. Meta-analysis for the changes in ESS regarding the different surgical techniques. 
Meta-analyses of relevant studies showed that the surgical technique that achieved the most reduction in $\mathrm{O}_{2}$ saturation was the expansion sphincter pharyngoplasty, with a significant mean reduction of [SMD $=1.011,95 \%$ CI $(0.581$ 1.440 ), p-value $<0.001$ ] (Figure 4). On the other hand, the surgical technique that achieved the worse reduction in $\mathrm{O}_{2}$ saturation was relocation pharyngoplasty, with a significant mean reduction of $[S M D=0.524,95 \%$ CI $(0.315-0.733)$, p-value $<0.001$ ] (Figure 4). The mean reduction of AHI for the classical UPPP was [SMD 0.990, 95\% CI (0.565 - 1.414), p-value < 0.001] (Figure 4). Random model was used, as heterogeneity was significant with $\mathrm{I}^{2}=82.776$, and $\mathrm{P}$-value $<$ 0.001 .

\section{4) VAS (Visual Analogue Scale) for Snoring}

Meta-analyses of relevant studies showed that the surgical technique that achieved the best reduction in VAS was Z-Palatoplasty, with a significant mean reduction of [SMD $=-1.551,95 \% \mathrm{CI}(-2.049--1.052)$, $\mathrm{p}$-value $<0.001]$ (Figure $5)$. On the other hand, the surgical technique that achieved the worse reduction in VAS was expansion sphincter pharyngoplasty, with a significant mean reduction of [SMD $=-4.579,95 \%$ CI $(-5.381--3.788)$, p-value $<0.001$ ] (Figure 5). The mean reduction of VAS for the classical UPPP was [SMD $-2.560,95 \%$ CI $(-3.059--2.061)$, p-value $<0.001$ ] (Figure 5). Random model was used, as heterogeneity was significant with $\mathrm{I}^{2}=94.172$, and $\mathrm{p}$-value $<0.001$.

\section{5) Soft Palate Length}

Meta-analyses of relevant studies showed that the UPPP surgical technique achieved soft palate length change with a significant mean reduction of [SMD = $-2.219,95 \%$ CI $(-2.730--1.708)$, p-value < 0.001] (Figure 6). While, relocation pharyngoplasty achieved reduction in soft palate length, with a significant mean [SMD $=-1.549,95 \%$ CI $(-2.063--1.035), \mathrm{p}$-value $<0.001]$ (Figure 6). Random model was used, as heterogeneity was significant with $\mathrm{I}^{2}=96.706$, and $\mathrm{p}$-value $<$ 0.001 .

\section{6) Success Rate}

Meta-analyses of relevant studies showed that expansion sphincter pharyngoplasty achieved the overall highest significant success rate [Event rate $=77 \%$, 95\% CI $(65.4 \%$ - 85.5\%), p-value < 0.001] (Figure 7). While, Z-Palatoplasty achieved the least success rate [Event rate $=52.5 \%, 95 \%$ CI $(20.1 \%-82.9 \%$ ] (Figure 7). Random model was used, as heterogeneity was significant with $\mathrm{I}^{2}=$ 73.015, and p-value $<0.001$.

\section{Discussion}

OSA management can be divided into surgical and non-surgical with the earliest surgical technique being the UPPP. Subsequent modifications to the original technique and introduction of novel techniques have all been aimed at achieving consistently higher success rates and fewer complications.

This study included papers published in the last 10 years, starting in 2008. The reason being that the majority of the techniques with the exception of the Lateral 
Pharyngoplasty and modifications on the original UPPP, were introduced starting 2007. Therefore, including earlier papers would have possibly skewed the results in favor of older techniques.

Meta-analysis for changes in minimal 02 saturation \% regards different surgical techniques

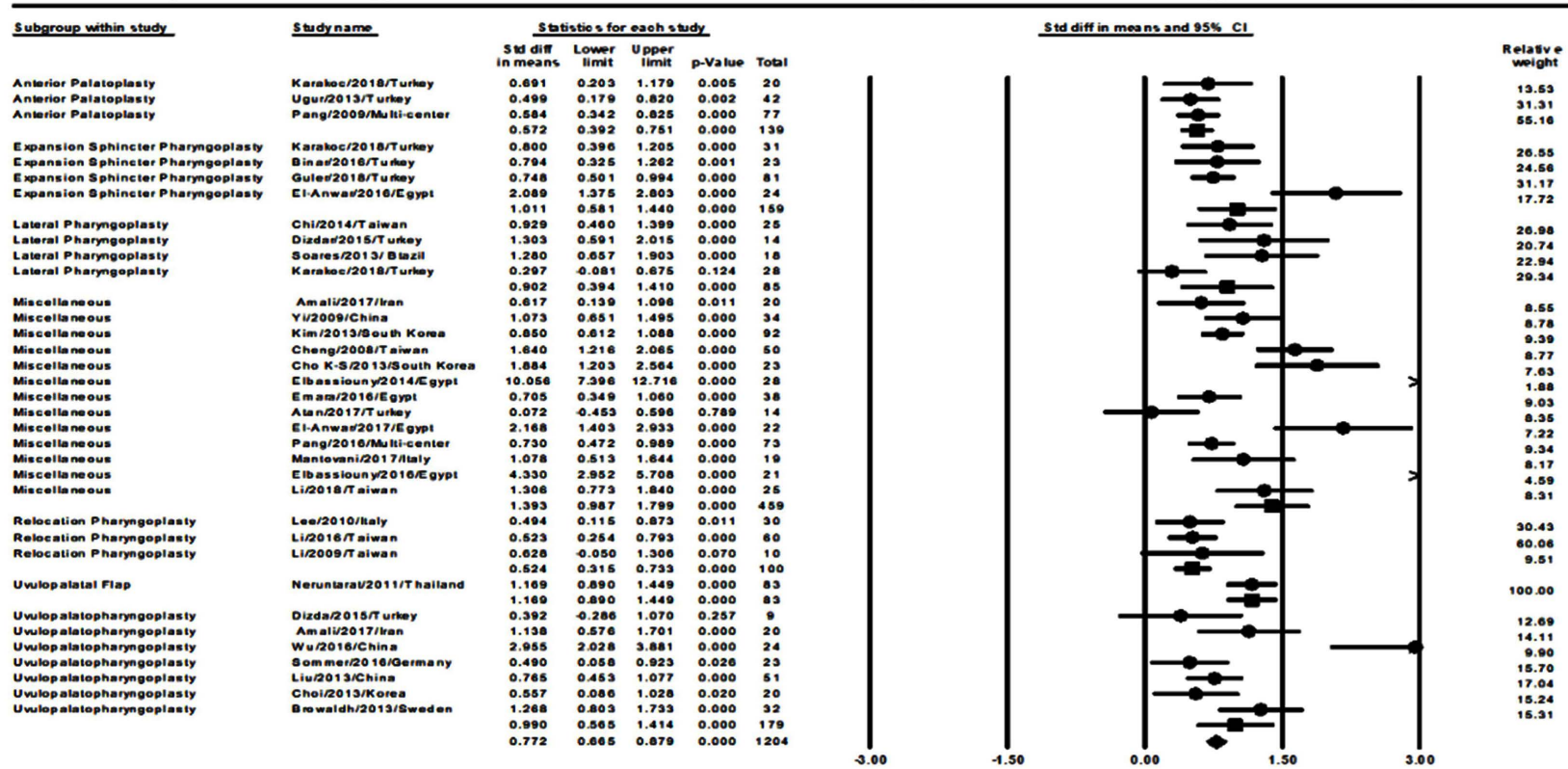

Random effe ct model, Hete roge neity: |^2=82.776, P-value $<0.001$

Figure 4. Meta-analysis for the changes in minimal oxygen saturation percentage regarding the different surgical techniques.

Meta-analysis for changes in VAS regards different surgical techniques

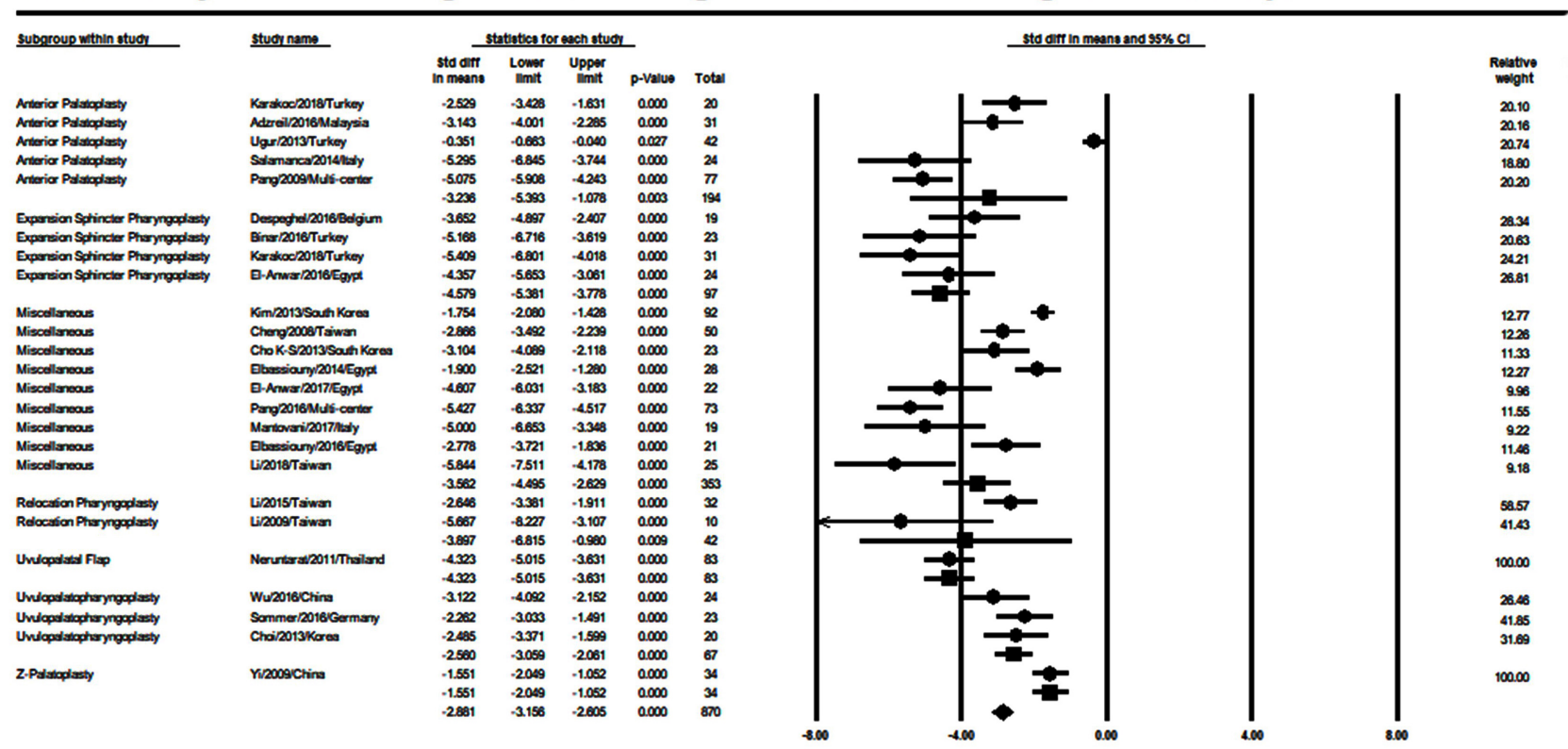

Random effect model, Heterogeneity: |^2=94.172, P-value<0.001

Figure 5. Meta-analysis for the changes in VAS for snoring regarding the different surgical techniques. 
Meta-analysis for changes in soft palate length regards different surgical techniques

\begin{tabular}{|c|c|c|c|c|c|c|}
\hline \multirow[t]{2}{*}{ Subgroup within study } & \multirow[t]{2}{*}{ Study name } & \multicolumn{5}{|c|}{ Statistics for each study } \\
\hline & & $\begin{array}{l}\text { Std diff } \\
\text { in means }\end{array}$ & $\begin{array}{c}\text { Lower } \\
\text { limit }\end{array}$ & $\begin{array}{c}\text { Upper } \\
\text { limit }\end{array}$ & p-Value & Total \\
\hline Missodlsnows & Cho K-S2013sauth Kroses & 11.220 & 8300 & 15200 & 0.000 & 23 \\
\hline \multirow[t]{2}{*}{ Misodloneass } & Emsa2016Egpt & .5013 & .6 .184 & .3862 & 0.000 & 3 \\
\hline & & 3233 & -13.173 & 19818 & 0.093 & 61 \\
\hline \multirow[t]{2}{*}{ Redocation Pharyopdxy } & Cherr2015T/siwen & -1.509 & .2003 & -1.035 & 0.000 & 32 \\
\hline & & -1.549 & .2063 & -1.035 & 0.000 & 32 \\
\hline \multirow[t]{3}{*}{ 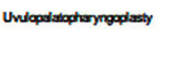 } & Luz2013ctina & .2219 & .2730 & -1.708 & 0.000 & 51 \\
\hline & & .2219 & .2730 & -1.708 & 0000 & 51 \\
\hline & & -1.894 & .2208 & -1.521 & 0.000 & 144 \\
\hline
\end{tabular}

Random effect model, Heterogeneity: I^2=96.706, P-value<0.001

Figure 6. Meta-analysis for the changes in soft palate length regarding the different surgical techniques.

Meta-analysis for success rate regards different surgical techniques

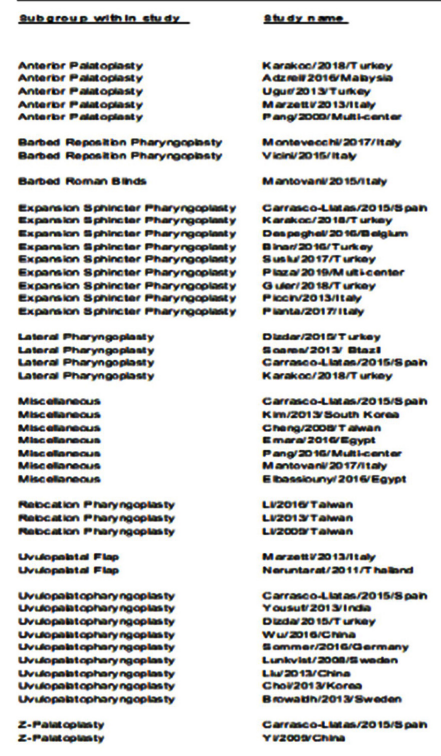

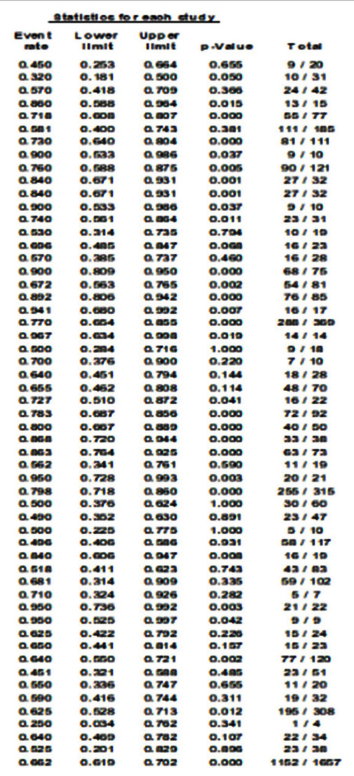
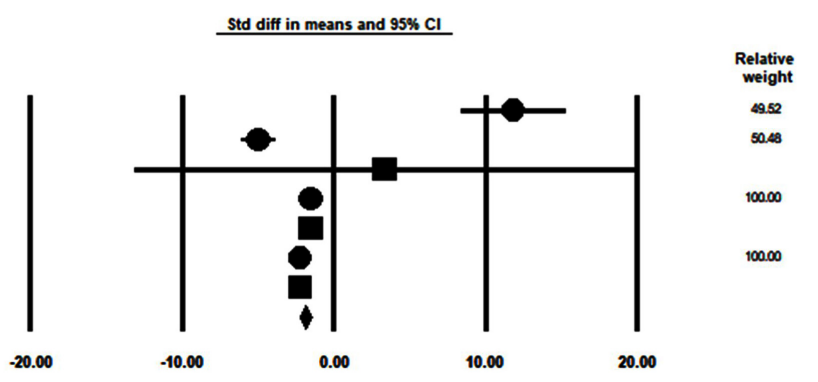

Random effect $m$ odel, Heterogeneity: |^2=73.015, P-value $<0.001$

Figure 7. Meta-analysis of the success rate regarding the different surgical techniques.

The success of palatal surgical techniques in treating OSA is graded according to improvements in different parameters. These namely being the AHI, ESS, Oxygen desaturation index \& VAS for snoring. Overall success in the majority of the papers was defined using Sher's Criteria introduced by Sher \& Colleagues in their 1996 publication [11]. The criterion states that surgical success for a given procedure is defined as $50 \%$ or more decrease in the AHI with a post-operative AHI less than or equal to 20/ hour. Based on Sher's criteria, our results show that the Expansion Sphincter Pharyngoplasty achieved the highest success rate. Our findings are consistent with those of other authors.

In 2018, Pang et al. published a Systematic review and meta-analysis which concluded that ESP resulted in better post-operative outcomes than other traditional surgeries, namely the Anterior Palatoplasty, Classical UPPP and Uvulopa- 
latal Flap procedures [12]. It should be noted, however, that this result is by no means universal, in the sense that not every patient suffering from OSAS will respond to ESP. There is no one-size-fits-all.

After reviewing the literature, several points of note have been identified:

- There is a general consensus that UPPP is no longer the best option for treating OSA. It is associated with significant post-operative pain and out of the previously discussed palatal surgeries has the highest risk of post-operative bleeding. Furthermore, UPPP can result in the much-disliked complication of velopharyngeal stenosis due to scar contracture according to Katsantonis, G. P., Friedman, W. H., Krebs, F. J., \& Walsh, J. K. (1987) [13].

- BRP is a quicker and easier technique to perform than the ESP and fully respects the anatomical integrity of the palate. It is also the technique associated with the least blood loss. The success of the BRP and ESP techniques stems mainly from the widening of the lateral retro-palatal diameters. That being said, despite the ESP achieving the highest success rate in our analysis, the ESP procedure has been associated food residues in the pyriform fossae due to interruption of the pharyngeal muscles that protect them [14].

- The Barbed roman blinds technique tensions the lateral wall without interrupting palatopharyngeal muscles unlike FEP and ESP and this tension occurs along the whole length of the thread. Barbed suturing allows muscles to be moved along different vectors (anteriorly, posteriorly, laterally) as required based on DISE evaluation.

- Pre-operative evaluation and identification of the site of obstruction is critical to optimizing post-operative results. DISE has proven to be the best diagnostic procedure suited to this purpose. By correctly locating the site of collapse the surgical technique that best addresses that site can be chosen and techniques which do not adequately address the pathological site can be avoided, even if it means forgoing palatal surgery altogether because the collapse is hypopharyngeal for example.

- There isn't always a single site of airway collapse and hence more than one surgery might be needed at different levels (multi-level surgery) to achieve a response.

- OSA severity can be graded as mild, moderate or severe. In many of the papers reviewed, authors would initially include only those patients with mild to moderate OSA. The main reasoning behind this was that they realized that the surgery they were proposing would not achieve adequate results in severe OSA patients. Nevertheless, this subsequently results in a distorted outcome.

- Some patients suffer from positional OSA. These patients tended to be in the mild to moderate group of OSA sufferers, whereas non-positional OSA subjects usually had severe OSA [15]. Consequently, positional OSA individuals tended to have higher post-operative success rates than their non-positional counterparts.

- Each procedure has its claimed advantages, however, objectively speaking, the best procedure would undoubtedly be the one that achieves the best 
post-operative results whilst minimizing palatal anatomical distortion and post-operative complications.

\section{Conclusion}

The best procedure for treating OSA varies from patient to patient and there is no universal cure-all. Careful patient selection and pre-operative evaluation are mandatory.

\section{Conflicts of Interest}

The authors declare no conflicts of interest regarding the publication of this paper.

\section{References}

[1] Guilleminault, C. and Abad, V.C. (2004) Obstructive Sleep Apnea Syndromes. The Medical Clinics of North America, 88, 611-630. https://doi.org/10.1016/j.mcna.2004.01.002

[2] Dickins, C. (1836) The Posthumous Papers of the Pickwick Club. Chapman and Hall, London.

[3] Rasmusson, L., Bidarian, A., Sennerby, L. and Scott, G. (2012) Pathophysiology and Treatment Options in Obstructive Sleep Apnoea: A Review of the Literature. International Journal of Clinical Medicine, 3, 473-484. https://doi.org/10.4236/ijcm.2012.36087

[4] Johnson, J.T. and Braun, T.W. (2008) Surgery for Obstructive Sleep Apnea. In: Myers, E.N., Ed., Operative Otolaryngology: Head and Neck Surgery, Saunders Elsevier, Philadelphia, 151-159. https://doi.org/10.1016/B978-1-4160-2445-3.50025-X

[5] Moher, D., Liberati, A., Tetzlaff, J. and Altman, D.G., The PRISMA Group (2009) Preferred Reporting Items for Systematic Reviews and Meta-Analyses: The PRISMA Statement. PLoS Medicine, 6, e1000097. https://doi.org/10.1371/journal.pmed.1000097

[6] Tawfik, G.M., Dila, K.A., Mohamed, M.Y., Tam, D.N., Ahmed, A.M. and Huy, N.T. (2019) A Step by Step Guide for Conducting a Systematic Review and Meta-Analysis with Simulation Data. Tropical Medicine and Health, 47, Article No. 46. https://doi.org/10.1186/s41182-019-0165-6

[7] Van Rijkom, H.M., Truin, G.J. and Van't Hof, M.A. (1998) A Meta-Analysis of Clinical Studies on the Caries-Inhibiting Effect of Fluoride Gel Treatment. Caries Research, 32, 83-92. https://doi.org/10.1159/000016436

[8] Borenstein, M., Hedges, L., Higgins, J. and Rothstein, H. (2005) Comprehensive Meta-Analysis: A Computer Program for Research Synthesis [Computer Software]. Biostat, Englewood, NJ.

[9] Begg, C.B. and Mazumdar, M. (1994) Operating Characteristics of a Rank Correlation Test for Publication Bias. Biometrics, 50, 1088-1101.

[10] Duval, S. and Tweedie, R. (2000) Trim and Fill: A Simple Funnel-Plot-Based Method of Testing and Adjusting for Publication Bias in Meta-Analysis. Biometrics, 56, 455-463. https://doi.org/10.1111/j.0006-341X.2000.00455.X

[11] Sher, A.E., Schechtman, K.B. and Piccirillo, J.F. (1996) The Efficacy of Surgical Modifications of the Upper Airway in Adults with Obstructive Sleep Apnea Syndrome. Sleep, 19, 156-177. https://doi.org/10.1093/sleep/19.2.156 
[12] Plaza, G., Pang, K.P., Baptista, P.M., Reina, C.O., Chan, H.Y., Pang, K.A., et al. (2018) Palate Surgery for Obstructive Sleep Apnea: A 17-Year Meta-Analysis. European Archives of Oto-Rhino-Laryngology, 275, 1697-1707.

[13] Katsantonis, G.P., Friedman, W.H., Krebs, F.J. and Walsh, J.K. (1987) Nasopharyngeal Complications Following Uvulopalatopharyngoplasty. The Laryngoscope, 97, 309-314. https://doi.org/10.1288/00005537-198703000-00009

[14] Sumida, K., Yamashita, K. and Kitamura, S. (2012) Gross Anatomical Study of the Human Palatopharyngeus Muscle Throughout Its Entire Course from Origin to Insertion. Clinical Anatomy, 25, 314-323. https://doi.org/10.1002/ca.21233

[15] Li, H., Cheng, W., Chuang, L., Fang, T., Hsin, L., Kang, C. and Lee, L. (2013) Positional Dependancy and Surgical Success of Relocation Pharyngoplasty among Patients with Severe Obstructive Sleep Apnea. American Academy of Otolaryngology, Head and Neck Surgery, 149, 506-512. https://doi.org/10.1177/0194599813495663 